\title{
Time to Strengthen Our Knowledge in the Areas of Acid-Base and Electrolytes
}

\author{
Qi Qianª, Zhi-Hong Liuc \\ a Department of Medicine, Division of Nephrology and Hypertension, Mayo Clinic College of Medicine, Mayo \\ Graduate School, and ${ }^{\mathrm{b}}$ The International Network of Diagnosis and Management of Acid-base, Electrolyte, and Fluid \\ Alterations, Rochester, Minn., USA; ' National Clinical Research Center of Kidney Disease, Jinling Hospital, Nanjing \\ University School of Medicine, Nanjing, China
}

Advances in life science in the 20th century have been formidable. We have expanded our knowledge from the 19th century Gregory Mendel's atom and gene theory to sophisticated gene mapping and genetically engineered designer treatment to alter a specific cellular target. The advances have been nothing short of miraculous. While the genetic community is to be congratulated for the extraordinary achievements, it must be acknowledged that molecular genetics is only one of many aspects of human inheritance. In fact, a majority of human diseases that directly impact health cannot be attributed simply to a single gene defect. They result, rather, from malfunctions in the multiplex of regulatory physiological and metabolic machinery, aspects of heredity critically important in maintaining human body homeostasis in health and disease.

Human health and disease are complex processes that often result from interplay between inheritance traits and environmental factors, and disturbances can and often do give rise to diseases. For instance, in response to the $\mathrm{Pa}$ leolithic diet [1-3], plant-based and with scanty concentrated calories and salt, humans have evolved physiologically and metabolically over several million years of terrestrial evolution to retain energy (from dietary carbohydrates) and sodium $\left(\mathrm{Na}^{+}\right)$. These evolutionary pres- sures have prepared the human body to deal effectively with caloric and salt deficits but have not prepared the body to cope with the sharp increase in dietary calories (fat and refined sugar) and salt that emerged with the rapid societal development and industrialization of the 20th century. Their excesses have been linked to a variety of chronic health problems and diseases including obesity, diabetes, hypertension, cardiovascular disease, osteoporosis and autoimmune disorders [4-7]. Sadly, beyond the dietary overabundance that marks modern lifestyles, excess salt infusion is often given to patients during the postoperative period and is associated with a number of adverse clinical outcomes, including mortality [8].

Paradoxically, although, in the medical community, we are well aware of the intricate molecular details of the gene expressions and cellular regulations of many electrolyte channels (i.e. $\mathrm{Na}^{+}, \mathrm{K}^{+}$and $\mathrm{Cl}^{-}$), we all too often fail to grasp some of their basic inherited physiological and metabolic regulatory traits. Indeed, studies evaluating provider knowledge have produced sobering results. Fewer than half of the hospital fluid/electrolyte prescribers were aware of the daily maintenance amounts of $\mathrm{Na}^{+}$, $\mathrm{K}^{+}$and fluids for an adult. Only $16 \%$ of the providers felt their knowledge sufficient to take on the task of prescribing fluid/electrolytes $[9,10]$. The first author of this Edi-

\section{KARGER}

E-Mail karger@karger.com

www.karger.com/kdd
2016 S. Karger AG, Basel

2296-9381/16/0022-0053\$39.50/0
Qi Qian, MD

Department of Medicine, Division of Nephrology and Hypertension

Mayo Clinic College of Medicine, Mayo Graduate School

200 First Street SW, Rochester, MN 55905 (USA)

E-Mail qian.qi@mayo.edu 


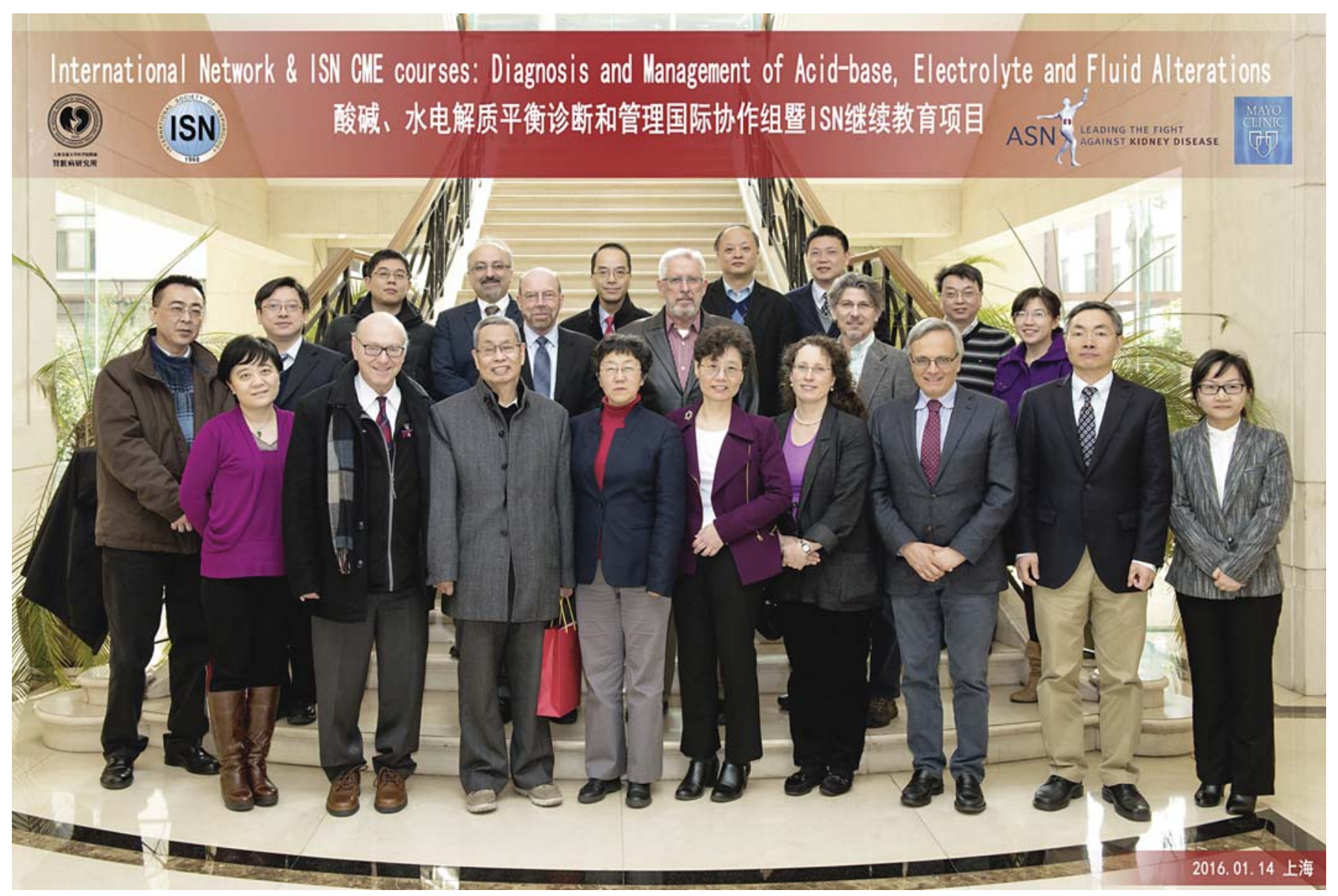

Fig. 1. A group photograph of the inaugural network meeting in Shanghai, China.

torial has personally observed such a knowledge deficiency in medical institutions in many countries.

The lack of adequate knowledge of this aspect of human traits translates to suboptimal care which can be detrimental to patients during our day-to-day delivery of care. This supposition was confirmed in a UK National Confidential Inquiry into Death Report, which concluded that fluid imbalance and inadequate electrolyte prescription contributed to serious postoperative morbidity and mortality.

Recognizing the knowledge inadequacy and its resultant adverse patient outcomes has led to the formation of the International Network of Diagnosis and Management of Acid-base, Electrolyte, and Fluid Alterations. Our goals are to refocus attention on the less-emphasized but fundamental aspects of human physiological and metabolic heredity, to provide health care professionals with integrated and translational updates, to foster cross-disci- plinary collaborative multicenter translational research focused in this area, to update guidelines and to provide periodic educational activities (case-based teaching and conference). Ultimately, we hope to raise the knowledge level of acid-base and electrolytes in the greater medical community, particularly in critical care medicine and nephrology.

The greater goals of the Network were articulated at the inaugural network group meeting in January 2016 in Shanghai, China (fig. 1). Experts (from Mayo Clinic College of Medicine, Brigham and Women's Hospital Harvard University, University of Southern California Medical Center, Kansas City University, Policlinico Hospital, 2nd University of Naples, Italy, Ruijin Hospital, Jiao Tong University, and a number of major universities in China) led by Prof. Qi Qian provided valuable input for the immediate and future plans of the network. The discussions were exhilarating as some of the greatest minds exchanged 
ideas, refined their thoughts and adopted suggestions from colleagues. We showcase three lectures in this issue of the journal presented at a Continuing Medical Education conference held in conjunction with the inaugural network activity, endorsed by the American Society of Nephrology and the International Society of Nephrology.

To close, although life science has enjoyed a quantum leap in knowledge of molecular insights in the last century, single gene mutations cannot account for the majority of human diseases. It is necessary to refocus on another important aspect of human heredity, physiological and metabolic regulatory machinery, specifically acidbase, electrolyte and fluid regulations that exert critical impact on human health and health-related outcomes. The formation of the network represents a step forward in strengthening our knowledge and promoting advances in this specialty area.

\section{Conflict of Interest Statement}

The authors have no conflicts of interest to disclose.

\section{References}

1 Eaton SB, Konner M: Paleolithic nutrition. A consideration of its nature and current implications. N Engl J Med 1985;312:283-289.

$\checkmark 2$ Sebastian A, Frassetto LA, Sellmeyer DE, Morris RC Jr: The evolution-informed optimal dietary potassium intake of human beings greatly exceeds current and recommended intakes. Semin Nephrol 2006;26:447-453.

$\checkmark 3$ Copeland SR: Potential hominin plant foods in northern Tanzania: semi-arid savannas versus savanna chimpanzee sites. J Hum Evol 2009;57:365-378.

$\checkmark 4$ Abete I, Astrup A, Martínez JA, Thorsdottir I, Zulet MA: Obesity and the metabolic syndrome: role of different dietary macronutrient distribution patterns and specific nutri- tional components on weight loss and maintenance. Nutr Rev 2010;68:214-231.

5 Appel LJ, Brands MW, Daniels SR, Karanja N, Elmer PJ, Sacks FM: Dietary approaches to prevent and treat hypertension: a scientific statement from the American Heart Association. Hypertension 2006;47:296-308.

6 Aaron KJ, Sanders PW: Role of dietary salt and potassium intake in cardiovascular health and disease: a review of the evidence. Mayo Clin Proc 2013;88:987-995.

7 Kleinewietfeld M, Manzel A, Titze J, Kvakan H, Yosef N, Linker RA, Muller DN, Hafler DA: Sodium chloride drives autoimmune disease by the induction of pathogenic TH17 cells. Nature 2013;496:518-522.
8 Callum KG, Gray AJG, Holie RW, Ingram GS, Martin IC, Sherry KM, Whimster F: Extremes of Age: The 1999 Report of the National Confidential Enquiry into Periopeartive Deaths. London, National Confidential Enquiry into Perioperative Deaths, 1999.

$\checkmark$ Lobo DN, Dube MG, Neal KR, Simpson J, Rowlands BJ, Allison SP: Problems with solutions: drowning in the brine of an inadequate knowledge base. Clin Nutr 2001;20: $125-130$.

10 Lobo DN, Dube MG, Neal KR, Allison SP, Rowlands BJ: Peri-operative fluid and electrolyte management: a survey of consultant surgeons in the UK. Ann R Coll Surg Engl 2002; 84:156-160. 